La mujer de la lágrima, de Elena Córdoba Citemor $/ 32^{\circ}$ Festival de

Montemor-o-velho, Teatro Esthér de Carvalho 2010 (Maria José Pire

e Elena Córdoba) fot Susana Paiva/Citemor.

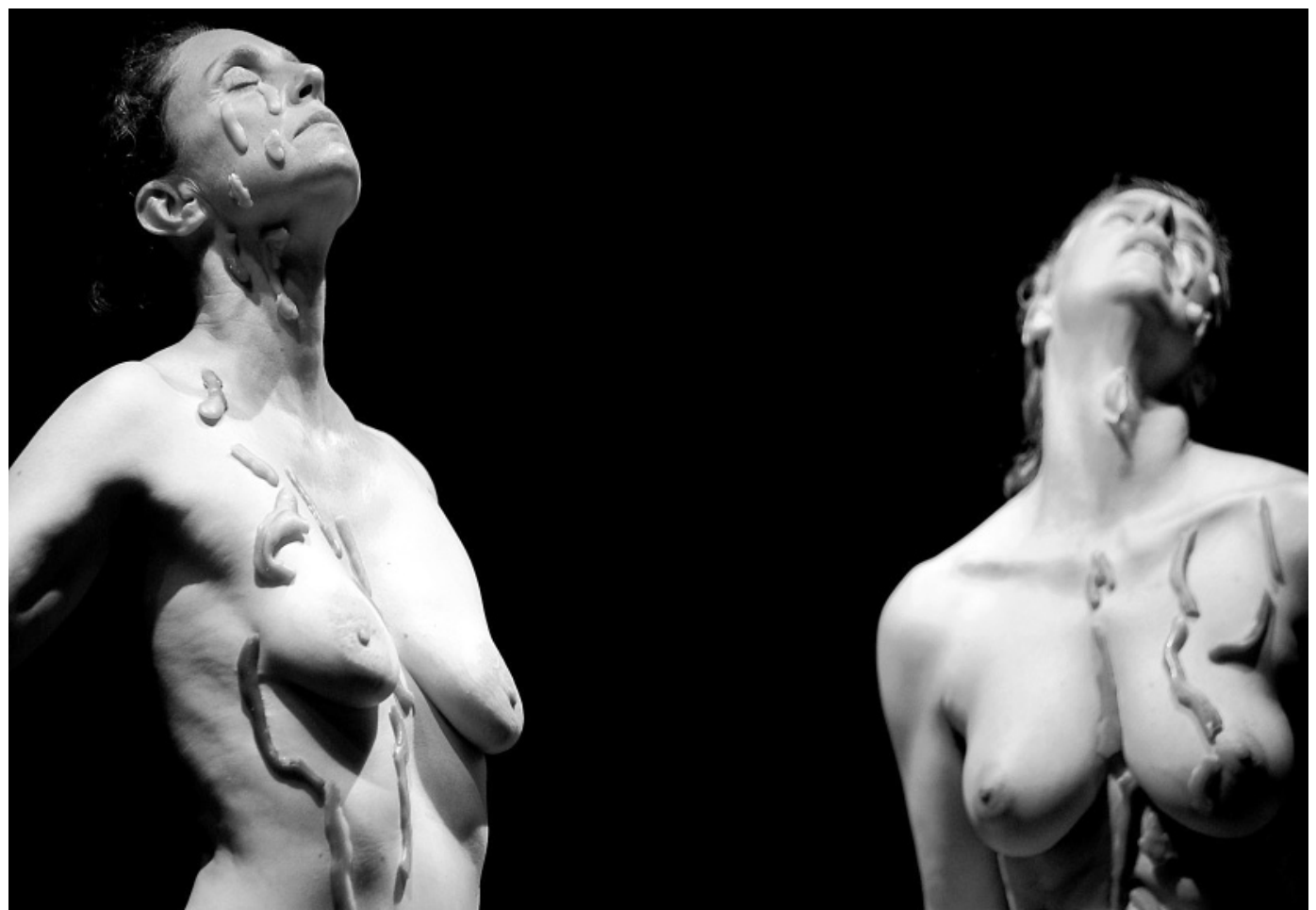

\title{
A poética anatómica dos corpos de Elena Córdoba
}

\author{
Vanessa Lourenço
}

Titulo: La mujer de la lágrima. "Siete piezas macabras»: video de Sylvia Calle. «Danzas macabras»: Elena Córdoba e Maria José Pire. Textos em vídeo: San Juan de la Cruz "Cántico espiritual" e Alain "Sobre la imaginación". Iluminação: Carlos Marquerie Música: György Ligeti. Desenho de projecção: Ramón Diago. Fotografia: Rafael Gavalle. Apoio: Instituto Cervantes (Madrid e Paris) e Ministerio de Asuntos Exteriores. Local e data de estreia: Teatro Esthér de Carvalho, Montemor-o-velho, 5 de Agosto de 2010

Título: Todo lo que se mueve está vivo. Direcção: Elena Córdoba. Bailarinas: Camille Hanson, Carme Torrent e Getsemani de San Marcos. Iluminação: Carlos Marquerie. Fotografía: Rafael Gavalle. Assistente de direç̧ão e cronista: Fernando Molina. Local e data de estreia: Espaço Mota-Engil/Real Estate, Montemor-o-velho, 12 Agosto de 2010. Obra criada no âmbito de ETC - Espacio de Teatro Contemporáneo da Sala Cuarta Pared (Madrid).

Titulo: Expulsadas del Paraíso. Bailarinas: Montse Penela, Camille Hanson e Elena Córdoba. Iluminação: Carlos Marquerie. Direcção: Elena Córdoba. Assistente de direcção: Maria José Pire. Agradecimento especial: Professor Cristóbal Pera. Obra financiada por: Comunidad de Madrid. Co-produção: Citemor. Local e data de estreia: Espaço Mota-Engil/Real Estate, Montemor-o-velho, 12 de Agosto de 2010.

0 Festival Citemor, em Montemor-o-Velho, teve este ano a sua $32^{a}$ edição. Trata-se de um evento com longa tradição no panorama teatral português, detendo um papel assinalável no campo da experimentação e das residências criativas. Centramos sobretudo a nossa atenção no percurso de Elena Córdoba, uma criadora já com historial em Montemor. Esta é também uma das linhas de acção que vem conferindo identidade ao evento de Montemor-oVelho: a estratégia de programação permite-nos o

Vanessa Lourenço é licenciada em Estudos

Artísticos pel Faculdade de Letras da

Universidade de

Coimbra. acompanhamento crítico do percurso de um artista ao longo do tempo e contribui em simultâneo para a visibilidade de novos projectos.

De regresso após 4 anos, Elena Córdoba apresentanos agora La mujer de la lágrima, Todo lo que se mueve está vivo e Expulsadas del Paraíso - tendo esta última criação resultado de uma residência de criação. Além destes espectáculos, tivemos ocasião de assistir à exibição de um conjunto de vídeos intitulado Museus do silêncio, elaborados em parceria com a realizadora Sylvia Calle, justamente sobre os museus de anatomia em França, Itália e nos Institutos de Anatomia da Faculdade de Medicina da Universidade de Coimbra. Estas obras têm vindo a coincidir numa linha de trabalho que a autora reúne sob o nome de Anatomia poética, um projecto de cariz experimental de que se ocupa há já alguns anos.

Abrindo um caminho sobre a percepção do corpo e do sentir, exibindo a corporeidade mais absoluta com manifesta sensibilidade poética, Córdoba procura o limite dos músculos e da vida, os contornos da forma, revelando assim o reverso da sua experiência e das suas vivências. 


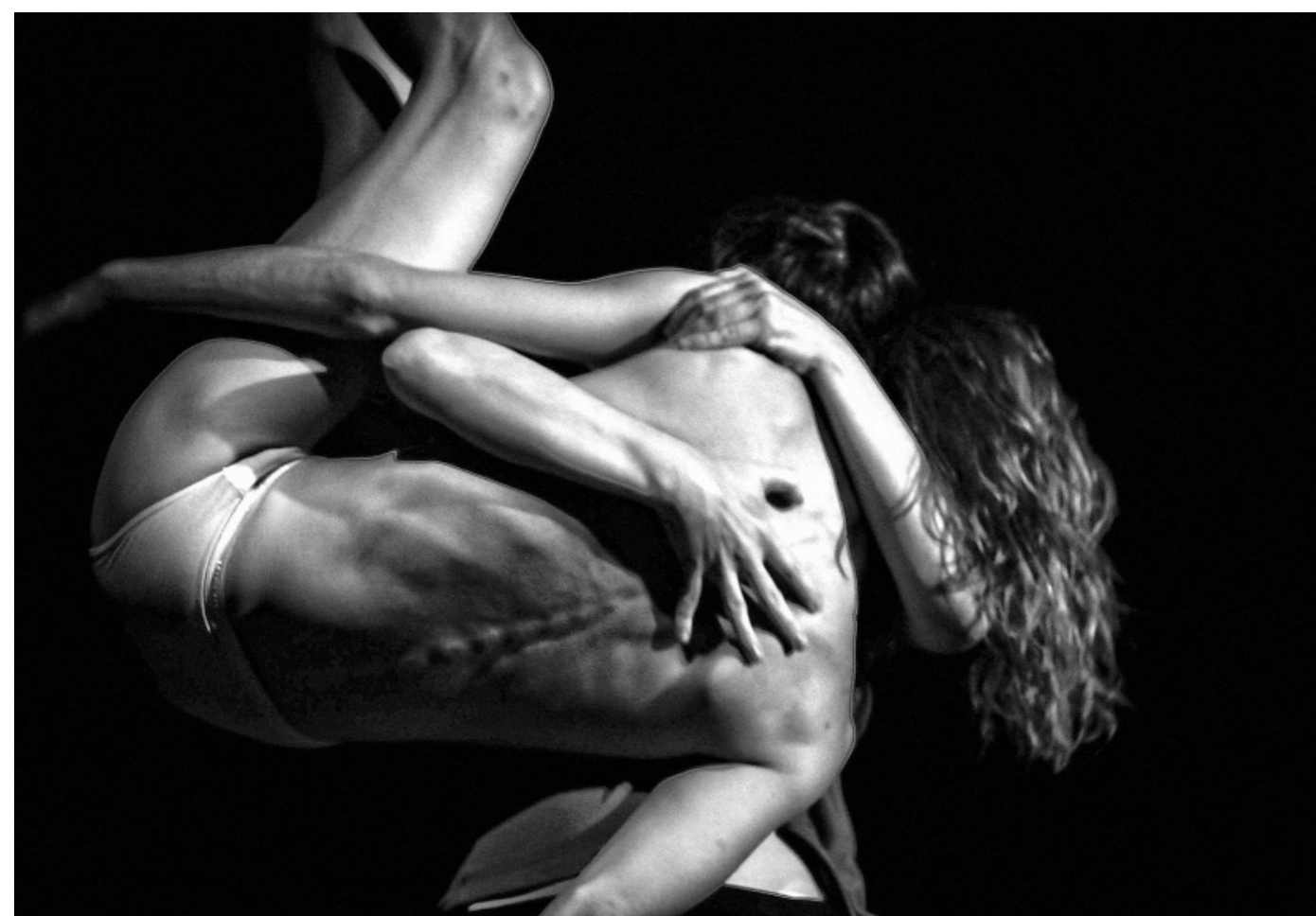

Todo lo que se mueve

está vivo,

de Elena Córdoba,

Citemor / $32^{\circ}$ Festival de

Montemor-o-velho,

Espaço Mota-Engil/Real

Estate, 2010

(Camille Hanson

e Getsemani de San

Marcos),

fot. Susana Paiva/Citemor
Partimos fundamentalmente de um discurso sobre a representação e sobre as formas da percepção. 0 que observamos evidencia o desejo de um diálogo entre a realidade e a imaginação, expondo a dualidade entre 0 objecto mais físico e o modo como percepcionamos o mundo ou como este nos é dado a conhecer.

Nesta poética anatómica questiona-se a fronteira entre o concreto e o sensivel; caminham lado a lado os textos científicos e a linguagem poética, as figuras anatómicas e os corpos em cena. 0 que será mais verdadeiro? Em que plano co-existem os corpos de cera que vemos representados e o corpo das performers? 0 espectador pode relacionar-se com a dança, os textos e os vídeos, sendo convocado para uma investigação que mobiliza tanto o abstracto como o sensível. Não sendo uma autora que faça da tecnologia pretexto para um manifesto multimédia em palco, utiliza ainda assim, com simplicidade notável, diversos modelos de registo do real, para ai investir uma espécie de meta-comentário sobre a representação e a percepção.

Em La mujer de la lágrima temos já os indícios disto mesmo na figura anatómica que inspira a peça: um busto de mulher com apenas metade do rosto a chorar uma lágrima. Nesta criação, Córdoba partilha o palco com outra mulher, María José Pire, explicitando também assim a dualidade heterónima presente em todo o espectáculo. A figura melancólica composta de cera expõe a dicotomia entre o corpo irreal e a emotividade da lágrima que nos implica e sensibiliza. Num dos vídeos projectados, uma voz masculina verbaliza esse prenúncio: "A visão de uma ferida horrivel altera o rosto do espectador e esse rosto, por sua vez, anuncia o horrivel e toca o diafragma do espectador, antes mesmo que este último dê conta do que o outro vê". É como que uma chamada de atenção, que se transforma em dúvida inquietante: Elena relaciona e faz sentir a dor como problema do corpo de que nós próprios dispomos. A dada altura recria uma série de movimentos, imitando a pose de bonecos anatómicos, enquanto Pire disseca cuidadosamente um pedaço de carne ao fundo do palco. É quase impossível dissociar estas duas acções, que constituem o momento decisivo da obra, iluminando os trabalhos que se seguem. Como essas figuras anatómicas, Elena Córdoba levanta as camadas da pele enquanto camadas de sentimentos, para mostrar em palco o interior que tentamos esquecer, o tempo que passa aos nossos olhos e através dos nossos sentidos.

Cada uma das três criações pede ao público que recorde e reflicta sobre as constantes da vida.

Córdoba demarca a anatomia com sensualidade e com uma gestualidade própria. Mais do que o gesto do dia-a-dia, sugere-nos o movimento invisivel que nos move e que tendemos a esquecer no ruído quotidiano. Todo lo que se mueve está vivo realiza-se num armazém de obras, vazio e cinzento, nos arredores de Montemoro-Velho.

0 silêncio e o frio propiciam um ambiente único, que se cola perfeitamente à geometria da peça, aos corpos que a habitam. Uma única luz sobre o corpo branco, em cuecas, é elevado lentamente pelos pés, ficando pendurado de costas para o público. Aquela estrutura óssea, vincada na pele que se reflecte em branco acinzentado e frio, surgenos com uma aura quase religiosa. A luz inicial diminui então de intensidade, aparecendo um segundo foco sobre uma segunda performer que despe o top, também de costas: contorce o braço, a omoplata, o ombro, o cotovelo, o pulso e a mão. 0 corpo mostra-se e experimenta-se como anatomia, exercício duplicado pelo que se encontra pendurado no início, contorcendo-se, demarcando várias partes dos braços e das costas, modelando carne e emoções.

Os dois corpos passam a interagir, abraçando-se. Apoiando-se um no outro, procuram tensões, delicadeza, emoções. Beijam-se e recriam uma espécie de Pietà: a performer que se encontra pendurada, agora a um nível 
Expulsadas del Paraiso,

de Elena Córdoba,

Citemor / $32^{\circ}$ Festival de

Montemor-o-velho,

Espaço Mota-

Engil/Real Estate, 2010

(Montse Penela),

fot. Susana Paiva/Citemor.

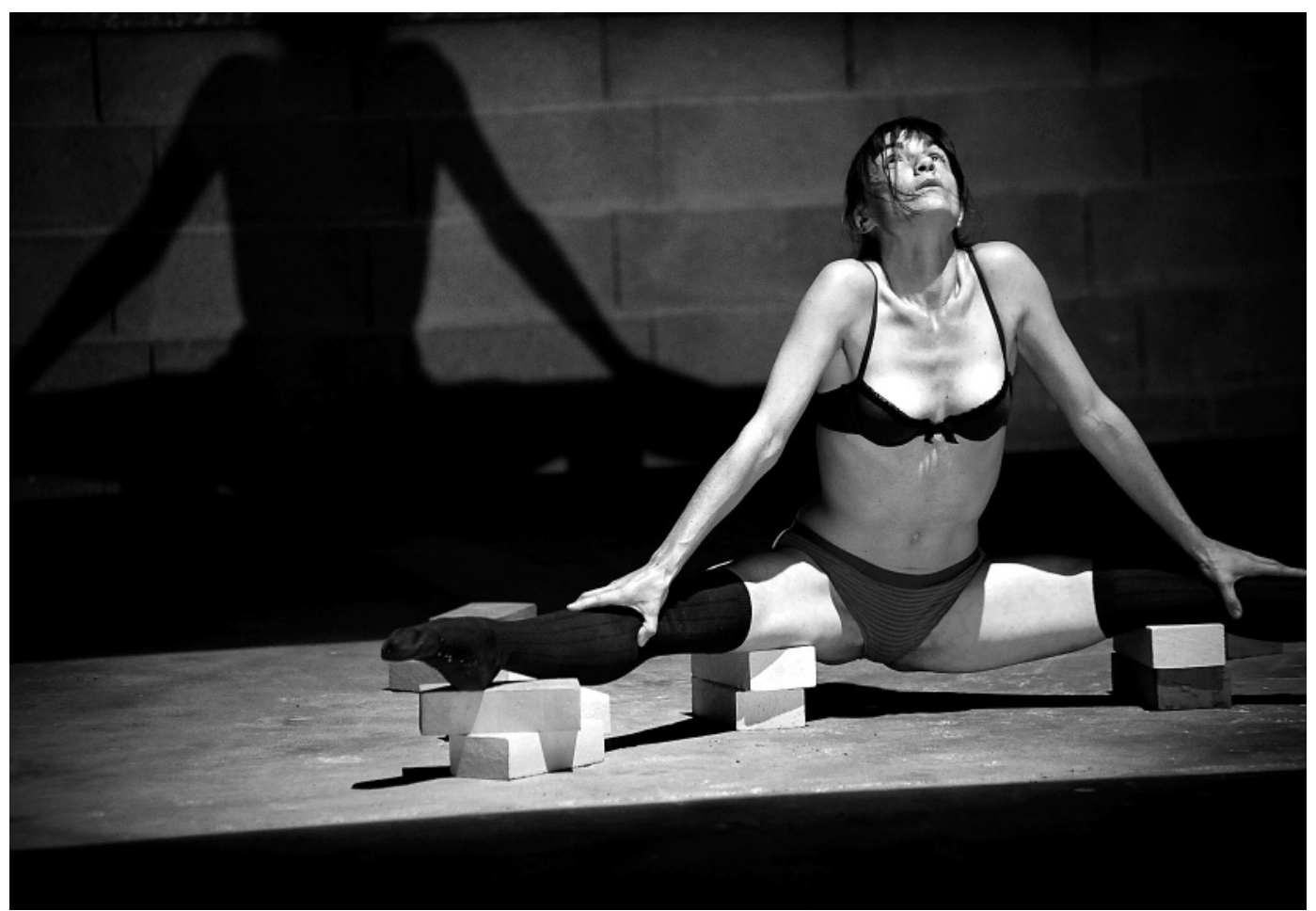

mais baixo, quase que se coloca no colo da sua companheira, numa relação de confiança, de força, resistência e balanço. Leia-se a autora, no blogue associado ao trabalho Anatomia poética:

Trabajo a partir de la resistencia que encuentro en los movimientos.(... Como si me fuera ejercitando para encontrarlas sensuales, como si fueran a ser mis compañeras de baile.

Em Expulsadas del Paraíso esta temática continua em evidência, agora servindo o ventre, as ancas, as entranhas.. Duas actrizes em palco, sob luzes vermelhas, delimitando geometricamente rectângulos e janelas voyueristas, como quadros luminosos, vitrinas nas quais as duas mulheres expõem o corpo como numa exposição anatómica. Uma bailarina vai empilhando tijolos no chão, enquanto estende as suas pernas afastadas sobre eles; força a elasticidade e o equilibrio. A outra dança sobre a estrutura das suas ancas, das suas junções, levantando uma perna, deslocando-a até ao máximo da sua capacidade. Estas peças desenham os contornos de morfologias, lembrando a certa altura a intensidade dos corpos expostos na obra de Egon Schielle: a fisicalidade angular cruza-se com a insinuação voluptuosa.

Como temos vindo a observar, os movimentos das bailarinas são como que auto-suficientes e celebram a fisiologia dos corpos através da potência dos músculos, da visibilidade das vértebras e dos ossos. Denotando a sua delicadeza estranha e algo de ironia, Elena Córdoba cria um momento singular quando coloca uma bailarina a beber água agitando o corpo frente a um microfone, deixando o público ouvir o próprio ruido da digestão. Os sons interiores servem nestas criações como um guia entre o temor e a beleza da carnalidade do ser. Já em La mujer de la lágrima Elena e Maria José Pire, sentadas frente ao público, se haviam encontrado em transe excessivo, num instante em que os corpos se derretem e se prendem à vida. Córdoba sonoriza frequentemente, geme, busca ar e engasga-se em murmúrios interiores. Trata-se de um som quase gutural, com origem no interior mais profundo.

Ao colocar o acto de comer, a digestão e o respirar em palco, Elena tenta chegar através da exploração da fisiologia à respiração mais profunda e invisivel do corpo. 0 acto de tocar e explorar o corpo adquire uma tonalidade ritualista, como que transpondo para a cena a aura reveladora dos museus anatómicos. Desde 0 princípio do espectáculo La mujer de la lágrima, uma placa de cera derrete lentamente para o chão sobre um suporte aquecido por velas. 0 som gotejante ecoa e, ao escorrer segundo a segundo, a cera solidifica de novo, até ser mais tarde preciosamente colada ao tronco nu de Córdoba e de Pire. Desta forma criam-se padrões anatómicos: cada uma constrói um mapa sobre o seu rosto, seio, pescoço, tronco e ventre. Cada uma é metade da outra; cada uma verte a lágrima da figura de cera que acima descrevemos. Ambas as figuras actuam também como bonecos anatómicos diante de nós, denunciam a vida que se esvai no "museu" da vida; por isso ouvimos um som de fundo, imitando os passos e as falas no museu. Córdoba e Pire viram os bonecos de cera, os seus corpos abertos e expostos. 0 público vê agora uma réplica na pele de ambas.

Em Expulsadas del Paraiso, Elena entra em cena, despe-se sob uma luz verde, contrastando com o ambiente quente que a precede. Despe-se lentamente, com o olhar intenso que tínhamos visto em La mujer de la lágrima, quando foca o público no início quase em transe. Criase assim um momento perturbante, frio e desprovido de qualquer impulso sexual. Elena Córdoba olha o público e activa cada um dos seus músculos. Não há pressa, o olhar surge perdido e determinado ao mesmo tempo. Não há prazer naquilo que se toca, apenas o silêncio, a lentidão da morte anunciada. E no entanto sobra uma delicadeza rara, bem como um questionamento inquietante. 